\title{
Tourism Value Evaluation of Urban Ancient Architecture
}

\author{
Pei Zhang \\ GSST, Kumamoto University, Kumamoto, Japan \\ Email:coocoobar@foxmail.com
}

How to cite this paper: Zhang, P. (2019). Tourism Value Evaluation of Urban Ancient Architecture. Current Urban Studies, 7, 157-169.

https://doi.org/10.4236/cus.2019.72007

Received: February 21, 2019

Accepted: May 28, 2019

Published: May 31, 2019

Copyright (C 2019 by author(s) and Scientific Research Publishing Inc. This work is licensed under the Creative Commons Attribution International License (CC BY 4.0).

http://creativecommons.org/licenses/by/4.0/

\begin{abstract}
Architecture has been regarded as one of basic prerequisites for urban tourism. Urban ancient architecture has all been attracted resources since the early times of tourism and performs important roles within the urban tourism system. However, not all the ancient relics have high tourism value, so it is necessary to make a scientific evaluation for urban ancient architecture from the perspective of tourism. This paper defined the concept of tourism value at first, and then constructed a tourism value evaluation system for urban ancient architecture from the perspective of tourism resources, finally took Chengdu, which is one of biggest cities in Western China, as a case study to evaluate the argument. This research shows that the tourism value evaluation index system of ancient architectures includes architectural noumenon value, tourism development value, historical value, artistic value, scientific value, cultural value, use value, emotional value and environmental value as well as the protection of the status quo, development conditions and 29-factor indexes. The historical background and the aesthetic value of the architecture are two main reasons for attracting tourists, and the research result shows that the consistent evaluation index system is scientific and feasible.
\end{abstract}

\section{Keywords}

Architourism, Tourism Value, Evaluation, Urban Ancient Architecture

\section{Introduction}

There is a close relationship between city and tourism, because cities are not only the largest sources of tourists but also the most significant tourist destinations (Edwards et al., 2008; Karski, 1990). Public statistics show that more than $90 \%$ of the tourists come from various types of cities, and most of cities which the tour- 
ists live in also become other tourists' destination by providing eating, lodging, traffic, sightseeing, shopping, and entertainment. The main reason for tourists visiting a city lies in the sightseeing, cultural exchanges, sports events, religious ceremonies, entertainment, shopping, personal errands, visiting relatives or friends, exhibitions, business meetings, conferences, etc. (Hall \& Page, 2006), and the area of the tourists' activity is usually located in the urban center, usually near the historic neighborhoods. Not only the historic buildings and cultural facilities, but also commercial and administrative facilities as well as convenient catering, transport and accommodation facilities are concentrated in these areas (Kurek, 2011), and the above distribution of the facilities reflects the main tourism service functions of the city. Tourists and various facilities that meet their needs define a series of different types of cities that may exist in specific urban areas, such as "shopping cities" and "historic cities" (Burtenshaw et al., 1991). Because of the variety of tourism supply, it is necessary to identify a wide range of various tourism motivation for travel in urban areas, from business tourism to cultural tourism, from leisure tourism to sports tourism, from shopping tourism to visiting relatives and friends, then to various combinations between these forms of tourism, which makes the variety and complexity of urban tourism.

Architecture plays a key role in creating a major recreation space for tourists, so it has been regarded as one of the most basic prerequisites for urban tourism. According to a survey, $63 \%$ of the tourists visiting a city will be directly related to architecture (Alexios et al., 2011). Not only that, the architecture is a major motivation for tourists to choose a travel destination. Due to the close connection between architecture and urban tourism, the academic circles coined the word "architourism" which was used to study architecture and tourism. The term was first mentioned in an academic conference, and architecture was regarded as a tourist destination to study American Architecture by Temple Hoyne Buell Centre in 2002. The success of Bilbao's Guggenheim which attracts the attention of global tourists and media by changing the city image and economy aroused the interest of the academic community on architourism. Since then, architourism has been the focus of attention and becomes a symbol to stimulate human beings' strong association (Chang, 2010). Urban ancient architecture, from Colosseum to St. Peter's church, from Pyramid to the holy city of Jerusalem, from the Forbidden City to the Tiantan of Beijing, has always been tourist attractions since ancient times (Jan, 2014). All the tourist cities have different kinds of architecture, especially the ancient architecture of the city with long history and rich cultural heritage. Urban ancient architecture plays an important role in the operation of the whole city's tourism system. It is not only a key "gateway" for both international and domestic tourists to understand a city, but also an important business card of the city image.

Urban ancient architecture is facing two different controversy arguments during the urban construction and the process of urban tourism development. On the one hand, urban ancient architecture is endowed with a great importance 
for the protection and inheritance of urban cultural heritage. On the other hand, it is a time-consuming and money-costing job to reinforce, repair, reconstruct urban ancient buildings as well as their daily management, and it may have little attraction to tourists. Generally speaking, every city has its own history and culture, ant it will leave a number of ancient buildings. From different point of view, urban ancient buildings may have different values. However, not all the ancient relics have high tourism value. For example, an ancient pagoda, it may have a very high historical value in the eyes of a historian; it may have a very high archaeological value in the eyes of an archaeologist; it may have a very high architectural value in the eyes of an architect; it may have a very high artistic value in the eyes of an artist. However, perhaps it has little tourism value in the eyes of individual mass tourist. After all, most ordinary tourists are not experts in every field. If the tourists couldn't get fun and interesting experiences from the ancient pagoda, they may feel bored and dull. Therefore, it is necessary to make a scientific evaluation for urban ancient architecture from the perspective of tourism, in order to make the right decisions in urban tourism planning, tourism development, policy-making processes and tourism marketing. In this paper, we will define the concept of tourism value at first, and then construct a tourism value evaluation system for urban ancient architecture from the perspective of tourism resources, and then take Chengdu, which is one of biggest cities in Western China, as a case study to evaluate the argument.

\section{Literature Review}

Value refers to the contribution of an object or action to a specific goal, objective, or condition, that is, the usefulness of the object to the subject. In tourism, the value of the object is the attractions of tourism, namely, tourism landscape, including natural tourism landscape and cultural tourism landscape; the value of subject is tourist, including individual subject, community subject and social subject. Therefore, the value of tourism is the effect of tourism object on the main body of tourism, or the role and influence of the tourism object. There are many English expressions for "tourism value", such as "tourism value", "tourist value", "travel value", "tourist attractions value", "recreational value", and so on. Similarly, it has also a lot of expressions of the "assessment", such as "assessment", "evaluation", "valuation", "estimation", and so on. From the semantic analysis, the evaluation is a process of structural explanation to predict whether the proposals or results are scientific or not. Costanza (2004) thinks that evaluation is the process of evaluating a specific object or action to achieve a specific goal's contribution, regardless of whether the contribution is fully perceived by the individual. Although there are some semantic differences between the above expressions, but in essence, it is mainly aimed at the tourist attractions. Generally speaking, the evaluation of the value of tourism resources is often expressed as the value of tourism resources, therefore, the evaluation of tourism value can also be called the evaluation of tourism resources. 
From the perspective of economy, tourism value evaluation mainly refers to the comprehensive evaluation and accounting aimed at the economic, ecological and social benefits provided by the tourism attractions. Early in 1667, British economist William Petty raised the "Cost-Benefit Analysis" theory, which was used for the economic evaluation of public sector investment and environmental impact. The theory also laid the basis for the evaluation of tourism value, from late 1970s to 80s, Travel Cost Method (TCM) was widely applied in related fields (Benson \& Willis, 1993). Since then, several evaluation methods also appeared, such as Hedonic Priced Method (HPM), Contingent Valuation Method (CVM), Benefit Transfer Method (BTM) and so on. TCM and CVM are the two most popular methods in the world among the assessment methods at present, and they were recommended twice to the federal government agencies as standard methods of recreational value evaluation in 1979 and 1983 by the American resources committee. These are discussed in turn below.

TCM (Travel Cost Method) is the first way to assess the benefits of non-price goods (especially outdoor entertainment). It is often used to evaluate the value of natural attractions and recreational environments that do not have a market price. TCM originated from the thought of Hoteling, which was proposed by American scholar Clausen at first in 1959 and then was introduced in the literature officially in 1996 (Clawson \& Knetsch, 1996). As an assessment of indirect method for recreational destinations (such as coasts, parks and Heritage Destinations), TCM evaluates tourism value according to a recreation destination "price" measured by travel expenses to the destination (Scarpa et al., 2000). The Marshallian Recreation Demand Curve explains the correlation between the cost of travel and the frequency of travel (Anex, 1995; Figure 1).

There are two main types of travel cost models, namely, the zonal travel cost method (ZTCM) and the individual travel cost model (ITCM). ZTCM depends on the number of trips brought to the site by the population of a specific area or region, but ITCM depends on the individual user who travels through an

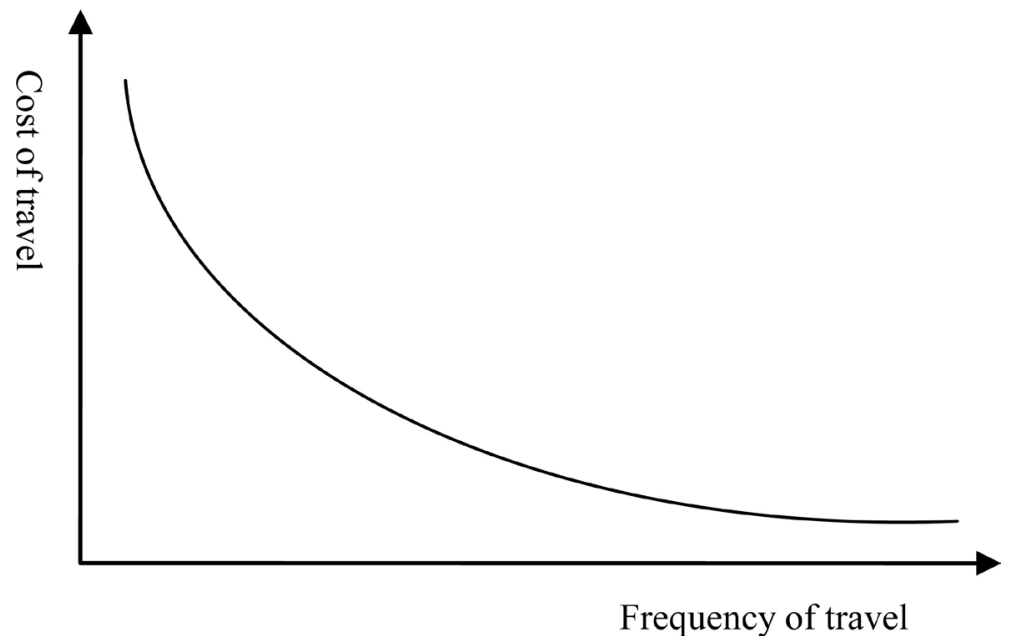

Figure 1. Marshallian recreation demand curve. 
entertainment site every year (or quarterly). The former is more suitable for remote access sites, and the latter is more suitable for frequent local visits (Fleming \& Cook, 2008). However, there are a lot of difficulties with using TCM in practical application, such as the cost of time, the visiting site per trip, the overseas visitors, and so on. All of them are variable with different situations.

CVM (Contingent Valuation Method) is the most widely used evaluation method of public goods in the ecological economics and environmental economics in recent years. As a kind of non-market value evaluation method, CVM is also called conditional value method. The method was originally proposed in 1947 by Ciriacy-Wantrup. For the first time, Davis applied CVM in practice in 1963 when he studied the entertainment value of Maine forest camping and hunting. Thereafter, two major values-selection value and existence value were widely recognized in the natural resources, which quickly became popular and were regarded as important methods for the evaluation of the total economic value of the environment in the economic literatures. Especially in 1960s, when some of the usual methods of revealing preferences (such as CMT) cannot assess some of the non-use value, the only way to evaluate these values is CVM (Venkatachalam, 2004). Since 1970s, CVM has gradually been used to evaluate the economic value of recreational, hunting and aesthetic benefits of natural resources (Carson, 1998). Most of countries, especially developed countries research shows that CVM is a very promising technology in helping public decision-making. As a standard method for the assessment of the economic value of non-market goods, CVM investigates or inquiries people's willingness to pay for a leisure, environmental improvements and measures for the protection of the resources, or willingness to accept (WTA), the mass loss of the environment or resource compensation to accept according to maximization principles. WTA reflects people's preference for non-market goods.

Due to the restrictions of cost, time, and other conditions, it is impossible to carry out an empirical study on the value evaluation of the tourism activities involved in the development of tourist attractions, so BTM (Benefit Transfer Method) came into being. The so-called "Benefit Transfer" will transfer the economic value of various resources or tourism activities from the study sites to the policy cites with statistics and econometrics methods. Of course, we have to try to seek a scenic spot research and policy scenic various conditions (include: population, economic income, natural conditions, consumer preference, and cultural practices, etc.) of the consistency in the process, and adjust the difference among them, to maximize the reduction value transfer error. This approach saves the time required for a lot of research cost and value evaluation, and makes investment decisions more quickly for the proposed the feasibility of investment projects, and makes tourism investment project value evaluation based on a unified appropriate standard, to avoid too much subjective intervention. Common value conversion methods include: Single Point Estimates, Average Value Transfer, 
Demand Function or Benefit Function Transfer and Meta-Analysis Benefit Functions. Rosenberger and Loomis (2004) calculated the range of a country or region and all kinds of tourism activities, mean consumer surplus or average value respectively by using the above four utility transfer methods in 2004, which provided an important reference for the future value evaluation of related tourism attractions. In addition, many American scholars used BTM to evaluate the economic value of the exploitation of tourism resources. For example, Philippines scholars Ahmed, Umali et al. (2007) studied the economic value of Philippines Lingayen Bay Coral Reef Resources in the Bolinao sea area by using the similar methods in 2007. The focus of the research is focused on the application of the model of value conversion, that is, the value of the use of the model is more accurate to predict the use of resource utilization. There is a reason to believe that BTM will play a greater role in the world's tourism resources recreation value evaluation research field in the future.

\section{Methodologies}

\subsection{Valuation Methods}

As most articles discussed in the above literature review, this paper will use a combination of valuation methods in order to calculate the value of urban ancient architecture for tourism, which is used by a Chinese researcher in 2014 (Xiao, Zhong, \& Yao, 2014). The tourism value of the urban ancient architecture includes two parts, that is, the building ontology value and the value of tourism development. The building ontology value covers historical value, artistic value, scientific value, cultural value, practical value and emotional value. The value of tourism development covers environmental value, conservation status and developmental condition. They can be further broken down into 29 indicators (Table 1). To reduce the deviation of index selection, we used the Delphi method and invited five architectural and cultural relics experts and 15 tourism academia and industry experts and got the most influential factors from the feedback of the experts. At the same time, in order to ensure that the evaluation index and the tourists' cognitive factors as much as possible, we interviewed with 30 tourists at random as an indicator of the revised reference.

\subsection{Survey Methods}

In order to investigate the ancient architecture, two methods of investigation were used in this paper. The first is a face-to-face survey that was used in Chengdu in the summer of 2017. Outbound tourists were invited to participate in a short interview (less than 10 minutes), and several questions were asked. Most importantly, e-mail addresses are required, which was necessary for online tracking. Online survey is a more extensive survey, with a median time of 18 minutes. The activities and impressions of ancient architecture were investigated, which verified the consistency of the answers. 
Table 1. The index system of tourism value evaluation of urban ancient architecture.

\begin{tabular}{|c|c|c|c|}
\hline Target layer A & Integrated layer B & Project level C & Factor layer D \\
\hline \multirow{29}{*}{$\begin{array}{l}\text { The index system } \\
\text { of tourism value } \\
\text { evaluation (A) }\end{array}$} & Building ontology value (B1) & Historical value $(\mathrm{C} 1)$ & Construction time (D1) \\
\hline & & & Historical figures and events (D2) \\
\hline & & & Social and historical background (D3) \\
\hline & & Artistic value (C2) & Architectural style (D4) \\
\hline & & & Beauty/sense of wonder (D5) \\
\hline & & & Architectural detail and decoration technology (D6) \\
\hline & & Scientific value (C3) & Building materials (D7) \\
\hline & & & Building technology (D8) \\
\hline & & & Spatial distribution (D9) \\
\hline & & & Building scale (D10) \\
\hline & & Cultural value (C4) & Cultural convergence (D11) \\
\hline & & & Culture type (D12) \\
\hline & & Emotional value (C5) & Religious worship (D13) \\
\hline & & & Architectural identity (D14) \\
\hline & & & Reputation (D15) \\
\hline & & Pragmatic value (C6) & History education/science popularization significance (D16) \\
\hline & & & Architectural openness (D17) \\
\hline & Tourism development value & Environmental value $(\mathrm{C} 7)$ & Tourism environmental capacity (D18) \\
\hline & & & Landscape region combination (D19) \\
\hline & & & Landmark (D20) \\
\hline & & & The role of environment and landscape formation (D21) \\
\hline & & Conservation status $(\mathrm{C} 8)$ & Conservation level (D22) \\
\hline & & & Protection technology level (D23) \\
\hline & & & Building integrity (D24) \\
\hline & & & The building of authenticity (D25) \\
\hline & & Development conditions (C9) & Accessible property (D26) \\
\hline & & & Supporting tourism facilities (D27) \\
\hline & & & Cost of building repair and maintenance (D28) \\
\hline & & & Ecological environment (D29) \\
\hline
\end{tabular}

Because this research not only involves the qualitative description of tourism resources, but also contains quantitative analysis of resource evaluation, the AHP (Analytic Hierarchy Process) analysis method can ensure the objective, scientific and accurate results of the research. We took the consistency test for the questionnaires by using software MATLAB and compared the survey of each evaluation index results with the arithmetic average score, and constructed the judgment matrix, calculation of the biggest feature of each matrix eigenvalue and 
eigenvector, finally obtained each index with respect to a layer of index's weights value. In the whole system, the final weight of each index is the product of the weight of the index and the weight of the upper level index (Table 2).

After determining the weight of each index of the evaluation system, it is necessary to evaluate the tourism value of the outstanding ancient architecture, and to rate each factor based on the questionnaire survey. In order to overcome the errors caused by different familiar degree, the familiar coefficient. In order to

Table 2. The weight of total sorts of tourism value evaluation index.

\begin{tabular}{|c|c|c|c|c|}
\hline Target layer A & Integrated layer B & Project level C & Factor layer D & Weight \\
\hline \multirow[t]{29}{*}{ A } & B1-0.60 & C1-0.16656 & D1 & 0.0211 \\
\hline & & & D2 & 0.0852 \\
\hline & & & D3 & 0.0563 \\
\hline & & C2-0.16656 & D4 & 0.0505 \\
\hline & & & D5 & 0.0796 \\
\hline & & & D6 & 0.0321 \\
\hline & & С3-0.03894 & D7 & 0.0085 \\
\hline & & & D8 & 0.0059 \\
\hline & & & D9 & 0.0083 \\
\hline & & & D10 & 0.0148 \\
\hline & & C4-0.05664 & D11 & 0.0215 \\
\hline & & & D12 & 0.0334 \\
\hline & & C5-0.07782 & D13 & 0.0237 \\
\hline & & & D14 & 0.0089 \\
\hline & & & D15 & 0.0426 \\
\hline & & C6-0.09348 & D16 & 0.0299 \\
\hline & & & D17 & 0.0615 \\
\hline & B2-0.40 & C7-0.15 & D18 & 0.0202 \\
\hline & & & D19 & 0.0317 \\
\hline & & & D20 & 0.0618 \\
\hline & & & $\mathrm{D} 21$ & 0.0317 \\
\hline & & C8-0.15 & D22 & 0.0496 \\
\hline & & & D23 & 0.0179 \\
\hline & & & D24 & 0.0303 \\
\hline & & & D25 & 0.0490 \\
\hline & & C9-0.1 & D26 & 0.0381 \\
\hline & & & D27 & 0.0187 \\
\hline & & & D28 & 0.0125 \\
\hline & & & D29 & 0.0269 \\
\hline
\end{tabular}


overcome the error caused by different familiar degree, this study introduces the familiar coefficient (Xiao, Zhong, \& Yao, 2014). Its value evaluation formula is:

$$
\begin{gathered}
C_{i}=\sum_{a=1}^{n} V_{a} f_{a} / \sum_{a=1}^{n} f_{a} \\
V=\sum_{i=1}^{m} C_{i} K_{i}
\end{gathered}
$$

In the above formula, $C_{i}$ is the final score of every index for architectural heritage; $V_{a}$ is the score of each index from respondents $a$ on the architectural heritage; $f_{a}$ is familiarity coefficient for each respondent; $K_{i}$ is the amount of relative value of each assessment index, namely weight coefficient $0<K_{i}<1 ; n$ is the number of surveyed respondents; $m$ is the number of evaluation index; $V$ is the integrated value for each of the heritage.

\section{Research Results}

\subsection{The Case Study Sites}

Chengdu, the capital of Sichuan Province, is famous for giant panda, teahouse, spicy food in China, and is the most relaxed city in China. Chengdu is located in the middle of Sichuan Province, which borders on Hubei, Hunan, Guizhou, Yunnan, Tibet, Qinghai, Gansu, Shaanxi and other provinces, with an area of 12,400 square kilometers and a population of about 10 million (Figure 2). Chengdu is also China's most important industrial base. Its industry is mainly in machinery, chemical industry, textiles, tools, computers, electronics, metallurgy, wood processing, etc.

To a large extent, the shape of Chengdu is like a circle, and the loop system is used. There are 5 main ring roads around the city, but most of them are located within the first three ring roads. Due to geographical location, Chengdu occupies an



Figure 2. Map of The Peoples Republic of China, highlighting the Sichuan province and Chengdu. 
important position in Chinese history. There are many beautiful historical sites in the city. Chengdu is not only the birthplace of tea culture, but also one of the earliest cities to use paper money, letterpress, natural gas and banks.

There are 5 main ring roads, but most of the city is situated within the first three. Because of its geographical location, Chengdu has played an important role in Chinese history and has many beautiful historical places within the city. Besides being the birthplace of tea-culture, Chengdu is also where paper money, relief printing, the use of natural gas, and one of the world's earliest banks were all founded. Using the evaluation system to conduct empirical research, this paper assesses 15 representative ancient architectures in Chengdu, such as Ancestral Shrine of the Qiu Family, Kang Jihong Mansion, Feng's Courtyard, Heming Teahouse, Former Office Building Cluster of CPC Chengdu Municipal Committee (Building No.5, No.6 and No.8), Former Site of Chengdu Municipal Government Offices, Xue's Mansion, Former Residence of Zhang Daqian and so on (Figure 3).

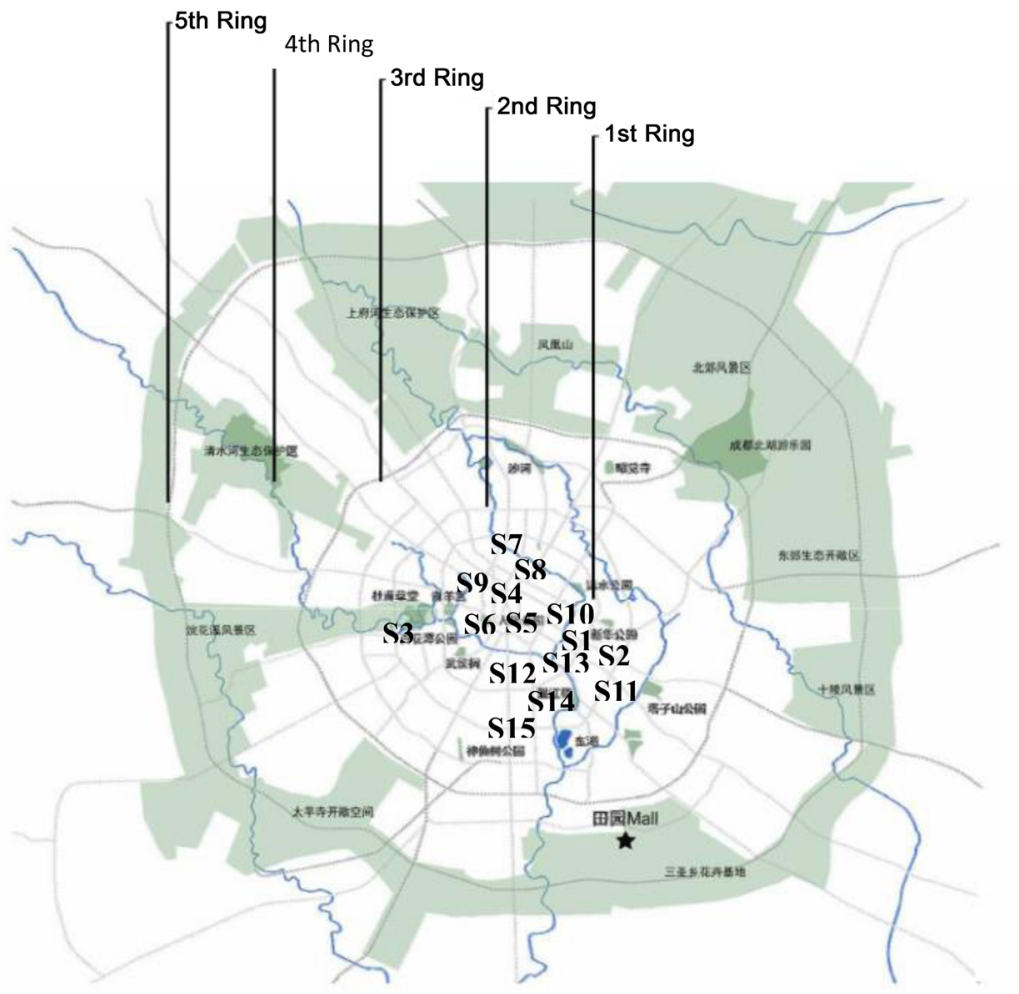

S1: Ancestral Shrine of the Qiu Family;

S2: Kang Jihong Mansion;

S3: Feng's Courtyard;

S4: Heming Teahouse;

S5: Former Office Building Cluster of CPC Chengdu Municipal Committee (Building No.5, No.6 and No.8);

S6: Former Site of Chengdu Municipal Government Offices;

S7: Xue's Mansion;

S8: Former Residence of Zhang Daqian;

S9: Former Office Building of Chengdu Electromechanical College;

S10: Xinlu Old Compound;

S11: Old Compound on Bitieshi Street;

S12: Chongdeli Community;

S13: Women Students' College, Sichuan University;

S14: Zhide Hall, Sichuan University;

S15: Institute of Chinese Studies, West China Union University

Figure 3. Map of Chengdu, showing the rings of the city and the research cities. 
Though the characteristic of contemporary Chengdu is a metropolis of China, its unique culture has been well protected. As an inland city, Chengdu maintains a more traditional culture than coastal cities and northern cities. This successful cultural protection is a difference, which makes Chengdu more interesting. Meanwhile, in the eyes of historians, Chengdu is also more significant. It represents a more typical Chinese city life (Wang, 2003).

2012, Chengdu is characterized by the guardian of "Sichuan in Sichuan", and the American times magazine once appraised Sichuan as "China's China” because of its traditional culture. The above shows that Chengdu is a modern city with unique culture preservation which makes it become a microcosm of modern Chinese cities. Chengdu not only represents the Sichuan Province, but also represents the whole country, which makes Chengdu a typical city for urban design and research in China, so it is a good example of central China, even the whole country.

\subsection{Research Results}

This research defined the criteria of evaluation index, each index was divided into 6 grades according to the value degree, and the 5 points, and the description of each level. The questionnaires were familiar with the weighted average after rounding, the evaluation object scores are shown in Table 3. According to the

Table 3. The score table of tourism value of ancient buildings in Chengdu

\begin{tabular}{ll}
\hline Ancient buildings & Comprehensive scores \\
\hline Kang Jihong Mansion & 4.8753 \\
Xinlu Old Compound & 4.7987 \\
Chongdeli Community & 4.5896 \\
Former Office Building Cluster of CPC Chengdu Municipal & 4.5488 \\
Committee (Building No.5, No.6 and No.8) & \\
Ancestral Shrine of the Qiu Family & 4.3891 \\
Heming Teahouse & 4.3233 \\
Former Residence of Zhang Daqian & 4.1567 \\
Feng's Courtyard & 4.1075 \\
Women Students' College, Sichuan University & 3.9808 \\
Former Site of Chengdu Municipal Government Offices & 3.8990 \\
Institute of Chinese Studies, West China Union University & 3.8557 \\
Former Office Building of Chengdu Electromechanical College & 3.7998 \\
Zhide Hall, Sichuan University & 3.7191 \\
Old Compound on Bitieshi Street & 3.6653 \\
Xue's Mansion & 3.4567 \\
\hline
\end{tabular}


final score high and low order, the top 6 (take the former 1/3) followed by: 1) Kang Jihong Mansion; 2) Xinlu Old Compound; 3) Chongdeli Community; 4) Former Office Building Cluster of CPC Chengdu Municipal Committee (Building No. 5, No. 6 and No. 8); 5) Ancestral Shrine of the Qiu Family; 6) Heming Teahouse. The evaluation results are basically consistent with the protection level of the cultural relics in Chengdu. We can also see the three characteristics of Chengdu ancient architecture: firstly, it is a large number and wide distribution, but the spatial agglomeration degree is higher, mainly concentrated in the downtown of Chengdu; secondly, it is variety from government agencies, public buildings, hotels to the residential houses; thirdly, it has a long history and beautiful shape, a variety of styles, exquisite materials, well preserved and generally high tourism value.

\section{Conclusion}

This research used the evaluation index system evaluated 15 ancient architectures in Chengdu, and the research results showed that the consistent evaluation index system is scientific and feasible. The tourism value evaluation index system of ancient architectures includes architectural noumenon value, tourism development value, historical value, artistic value, scientific value, cultural value, use value, emotional value and environmental value as well as the protection of the status quo and development conditions. The reasons for attracting tourists for ancient architectures lie in the specific historical background and its aesthetic value.

While attracting tourists, ancient architecture has attracted more and more attention from scholars, although the relevant research results are relatively rare. This study is only an attempt, and there are still many aspects to be improved, such as the index composition, assignment, weight and so on. At the same time, due to the influence of time, energy and financial resources, the sample scale is small, and the coverage is still incomplete, all of which are expected to deepen gradually in future research.

\section{Conflicts of Interest}

The author declares no conflicts of interest regarding the publication of this paper.

\section{References}

Ahmed, M., Umali, G. M., Chong, C. K. et al. (2007). Valuing Recreational and Conservation Benefits of Coral Reefs-The Case of Bolinao, Philippines. Ocean \& Coastal Management, 50, 103-118. https://doi.org/10.1016/j.ocecoaman.2006.08.010

Alexios, V., Sandra, K., \& Anagnostou, M. (2011). Public Space and Architectural tourism.

http://www.greekarchitects.gr/en/architraveling/public-space-and-architectural-touris $\mathrm{m}-\mathrm{id} 4287$

Anex, R. P. (1995). A Travel-Cost Method of Evaluating Household Hazardous Waste 
Disposal Services. Journal of Environmental Management, 45, 189-198. https://doi.org/10.1006/jema.1995.0067

Benson, J. F., \& Willis, K. G. (1993).Valuing Informal Recreation on the Forestry Commission Estate. Quarterly Journal of Forestry, 16, 63-65.

Burtenshaw, D., Bateman, M., \& Ashworth, G. J. (1991). The European City: A Western Perspective. London: David Fulton.

Carson, R. T. (1998). Carson Valuation of Tropical Rain-Forests Philosophical and Practical Issues in the Use of Contingent Valuation. Ecological Economics, 24, 15-29. https://doi.org/10.1016/S0921-8009(97)00584-3

Chang, T. C. (2010). Bungalows, Mansions and Shophouses: Encounters in Architourism. Geoforum, 41, 963-971. https://doi.org/10.1016/j.geoforum.2010.07.003

Clawson, M., \& Knetsch, L. J. (1996). Economics of Outdoor Recreation (p. 328). Baltimore, MD: John Hopkins Press.

Costanza, R. (2004). Value Theory and Energy. In Encyclopedia of Energy (Vol. 6, pp. 337-346). Amsterdam: Elsevier. https://doi.org/10.1016/B0-12-176480-X/00118-2

Edwards, D., Griffin, T., \& Hayllar, B. (2008). Urban Tourism Research: Developing an Agenda. Annals of Tourism Research, 35, 1031-1052. https://doi.org/10.1016/j.annals.2008.09.002

Fleming, C. M., \& Cook, A. (2008). The Recreational Value of Lake McKenzie, Fraser Island: An Application of the Travel Cost Method. Tourism Management, 29, 1197-1205. https://doi.org/10.1016/j.tourman.2008.02.022

Hall C. M., \& Page S. J. (2006). The Geography of Tourism and Recreation. Environment, Place and Space (3rd ed., pp. 248-250). London: Taylor \& Francis e-Library.

https://doi.org/10.4324/9780203420249

Jan, S. (2014). Architectural Tourism: Building for Urban Travel Destinations. Munich: Springer Gabler.

Karski, A. (1990). Urban Tourism: A Key to Urban Regeneration. The Planner, 6, 15-17.

Kurek, W. (2011). Turystyka (p. 325). Warszawa: Wydawnictwo Naukowe PWN.

Rosenberger, R. S., \& Loomis, J. B. (2004). Benefit Transfer of Outdoor Recreation Use Values. A Technical Documents Supporting the Forest Strategic Plan (2004 Revision). U.S. Department of Agriculture Forest Service.

Scarpa, R., Chilton, S. M., Hutchinson, W. G., \& Buongiorno, J. (2000). Valuing the Recreation Benefits from the Creation of Nature Reserves in Irish Forests. Ecological Economics, 33, 237-250. https://doi.org/10.1016/S0921-8009(99)00143-3

Venkatachalam, L. (2004). The Contingent Valuation Method: A Review. Environmental Impact Assessment Review, 24, 89-124. https://doi.org/10.1016/S0195-9255(03)00138-0

Wang, D. (2003). Public Space, Urban Commoners, and Local Politics (pp. 1870-1930). Redwood City, CA: Stanford University Press.

Xiao, X., Zhong, Y. S., \& Yao, R. T. (2014). The Tourism Evaluation System of the Modern Western Architecture in China and It's Empirical Analysis. Economic Geography, 34, 165-170. 